\title{
Comportamento de cultivares de morangueiro em Maria da Fé e Inconfidentes, sulde Minas Gerais
}

\author{
Joaquim Gonçalves de Pádua ${ }^{1}$ \\ Luiz Carlos Dias Rocha² \\ Emerson Dias Gonçalves ${ }^{3}$ \\ Thaís Helena de Araújo ${ }^{4}$ \\ Ezequiel Lopes do Carmo 5 \\ Rafaela Costa ${ }^{6}$
}

\section{Resumo}

A cultura do morango tem-se expandido rapidamente e inúmeras cultivares têm sido introduzidas na região sul de Minas Gerais. A maioria dessas introduções é feita sem avaliações prévias das condições ecológicas das regiões de cultivo, o que pode levar alguns produtores ao fracasso, visto que a escolha das cultivares é um dos pontos-chave para o sucesso esperado com a cultura. As características das cultivares aliadas às condições ambientais da região e ao manejo adotado determinam a produtividade e a qualidade do produto final, influenciando inclusive na comercialização, devido à preferência de alguns mercados por frutas com características específicas. Neste trabalho, objetivou-se avaliar os aspectos produtivos das cultivares Albion, Aleluia, Aromas, Camarosa, Camino Real, Festival, Oso Grande e Ventana, em Maria da Fé, na Fazenda Experimental da EPAMIG, e em Inconfidentes, na área experimental do Instituto Federal, na região sul de Minas Gerais. As cultivares de morango que mais se adaptaram às condições do Sul de Minas foram Ventana, por produzir mais frutos em Maria da Fé, e a cultivar Oso Grande, por produzir mais frutos em Inconfidentes. As cultivares Oso Grande e Camarosa apresentaram maior estabilidade, com bom potencial produtivo em ambos os locais, configurando como opções para diversificação do plantio e da produção. Os frutos das cultivares Camino Real, Festival, Oso Grande e Ventana foram maiores e mais doces quando produzidos em Maria da Fé, e as condições de cultivo em Inconfidentes proporcionaram frutos mais doces às cultivares Albion, Aleluia, Camino Real e Festival.

Palavras-Chave: Fragaria x ananassa Duch. Morango. Produção. Qualidade de frutos.

\section{Introdução}

1 EPAMIG - Núcleo Tecnológico de Batata e Morango, pesquisador. Pouso Alegre, Minas Gerais, Brasil. padua2008@gmail.com. (35) 3421-3791. Avenida Pref. Tuany Toledo, 470, Fátima I, Pouso Alegre, MG, CEP: 37550-000.

2 IFSULDEMINAS - Campus Inconfidentes, professor pesquisador. Inconfidentes, Minas Gerais, Brasil. luiz.rocha@ifsuldeminas.edu. br. (35) 3464-1200. Praça Tiradentes, 416, Centro, Inconfidentes, MG, CEP: 37576-000.

3 EPAMIG- Fazenda Experimental de Maria da Fé, pesquisador. Maria da Fé, Minas Gerais, Brasil. emerson@epamig.br. (35) 36621227. Rua Washington Alvarenga Viglione, s/nº, Vargedo, Maria da Fé, MG, CEP: 35517-000.

4 ESALQ/USP - Departamento de Produção Vegetal, pesquisadora de Doutorado. Piracicaba, São Paulo, Brasil. tharaujo@usp.br. (19) 3371-0378. Avenida Pádua Dias, 11, Piracicaba, SP, CEP:13418-900, Caixa Postal 09.

$5 \quad$ IFMT - Campus Campo Novo do Parecis, professor pesquisador. Campo Novo do Parecis, Mato Grosso, Brasil. ezequielcerat@gmail. com. (65) 8107-3307. Rodovia MT 235, Km 12, s/n, Campo Novo do Parecis, MT, CEP: 78360-000.

$6 \quad$ IFSULDEMINAS - Campus Inconfidentes, Graduanda em Agronomia. Inconfidentes, Minas Gerais, Brasil. costa.rafaela23@gmail. com. (35) 3464-1200. PraçaTiradentes, 416, Centro, Inconfidentes, MG, CEP: 37576-000. 
A cultura do morangueiro na região sul de Minas Gerais vem se consolidando predominantemente em pequenas propriedades, impulsionada pelas condições climáticas favoráveis, por sua localização privilegiada em relação aos grandes centros consumidores e pela boa rentabilidade proporcionada. Atualmente, é nessa região que são encontradas algumas das lavouras de morangueiro com as tecnologias mais avançadas do Brasil (DUARTE FILHO, 2006). No entanto, o sistema de produção do morangueiro tem apresentado algumas limitações quanto aos padrões técnicos, decorrentes da utilização de cultivares suscetíveis a doenças e pragas, responsáveis pelo excessivo uso de agrotóxicos, os quais, muitas vezes, geram consequências danosas ao meio ambiente e ao homem (COSTA; VENTU$R A, 2004)$. A sociedade tem priorizado o uso adequado de produtos de forma a evitar contaminações por produtos químicos e resíduos tóxicos nos alimentos, principalmente nos alimentos de consumo in natura, como é o caso do morango (OLIVEIRA, 2006). O produtor de morangos investe intensamente em tecnologia, visando a aumentar a produção da cultura, principalmente com a adoção de mudas com alto potencial produtivo (SANTOS; MEDEIROS, 2005).

A escolha das cultivares a serem utilizadas na exploração da cultura do morangueiro é um dos pontos-chave para se obter sucesso nessa atividade, pois serão as suas características que, aliadas às condições ecológicas da região e somadas ao manejo adotado, determinarão a produtividade e a qualidade do produto final (DUARTE FILHO, 2006). Segundo Oliveira e Bonow (2012), a adaptabilidade de uma cultivar a determinada região produtora é expressa pela interação genótipo-ambiente, e a interação entre temperatura e fotoperíodo determina a produtividade e a qualidade do fruto, as quais são influenciadas pelas condições de solo e pela incidência de pragas e doenças. Salienta-se ainda que esses resultados vão influenciar também na comercialização, devido à preferência de alguns mercados por frutos com determinadas características. Nos últimos anos, inúmeras cultivares vêm sendo introduzidas na região Sul de Minas, decorrentes dos diferentes programas de melhoramento em nível mundial. 0 grande problema dessas introduções é a falta de avaliações prévias das cultivares nas condições ecológicas das regiões de cultivo, o que, muitas vezes, pode levar alguns produtores ao fracasso (DUARTE FILHO, 2006).

Em condições de temperatura elevada, o fruto do morangueiro torna-se pobre em sabor e aroma, tem menor consistência e é excessivamente ácido. 0 frio, ao contrário, torna o sabor e aroma do morango mais pronunciados, além de apresentarem maior firmeza (FILGUEIRA, 2000). Portanto, verificar o comportamento de cultivares de morango em municípios como Maria da Fé e Inconfidentes é de grande importância, pois apresentam condições climáticas favoráveis ao cultivo, podendo proporcionar alternativa econômica e social para a região. Além disso, apresentam facilidade de escoamento e comercialização da produção, por estarem próximos de grandes centros consumidores.

Com este trabalho, objetivou-se avaliar os aspectos produtivos e de qualidade das cultivares Albion, Aleluia, Aromas, Camarosa, Camino Real, Festival, Oso Grande e Ventana em Maria da Fé, na Fazenda Experimental da EPAMIG, e em Inconfidentes, na área experimental do Instituto Federal, na região sul de Minas Gerais.

\section{Material e Métodos}

Os experimentos foram conduzidos no ano de 2009, em ambiente protegido sob túneis baixos cobertos com polietileno transparente de baixa densidade (PEBD), com espessura de $100 \mu \mathrm{m}$, os quais foram instalados em dois locais: em Maria da Fé, na Fazenda Experimental da Empresa de Pesquisa Agropecuária de Minas Gerais - EPAMIG, e em Inconfidentes, na área experimental do Instituto 
Federal de Educação, Ciência e Tecnologia do Sul de Minas Gerais-IFSULDEMINAS.

O município de Maria da Fé (latitude: 22¹8'29" S; longitude: 45²2'31" O; e altitude: $1.276 \mathrm{~m}$ ) está localizado na microrregião da Serra da Mantiqueira, sul do estado de Minas Gerais. Apresenta relevo predominantemente montanhoso e classificação climática, segundo Köppen, do tipo Cwb, ou seja, clima temperado chuvoso (mesotérmico), também chamado subtropical de altitude. Caracteriza-se ainda por apresentar temperatura média anual em torno de $17^{\circ} \mathrm{C}$, temperatura máxima de $23,3{ }^{\circ} \mathrm{C}$ e mínima de $10,1^{\circ} \mathrm{C}$ e precipitação anual de $1.738,6 \mathrm{~mm}$. Nesse local, o experimento foi instalado em solo classificado como Latossolo Vermelho Distroférrico de textura argilosa, cuja análise química resultou: $\mathrm{pH}$ (água) $=6,1 ; \mathrm{P}=4,3 \mathrm{mgdm}^{-3} ; \mathrm{K}=86,0 \mathrm{mgdm}^{-3} ; \mathrm{Ca}=3,0 \mathrm{cmol}_{\mathrm{c}} \mathrm{dm}^{-3} ; \mathrm{Mg}$ $=1,1 \mathrm{cmol}_{c} \mathrm{dm}^{-3} ; \mathrm{Al}=0,0 \mathrm{cmol}_{c} \mathrm{dm}^{-3} ; \mathrm{H}+\mathrm{Al}=3,6 \mathrm{cmol}_{\mathrm{c}} \mathrm{dm}^{-3} ; \mathrm{SB}=4,3 \mathrm{cmol}_{c} \mathrm{dm}^{-3} ; \mathrm{T}=7,9 \mathrm{cmol}_{\mathrm{c}} \mathrm{dm}^{-3}$; $\mathrm{V}=54,5 \% ;$ M.O. $=2,4$ dagkg $^{-1}$.

O município de Inconfidentes (latitude: 22¹9’02" S; longitude: 46¹9'42" O; e altitude: $869 \mathrm{~m})$, também localizado na região Sul de Minas, apresenta relevo ondulado e montanhoso. A classificação climática, segundo Köppen, é do tipo Cwb, clima subtropical de altitude, com verão chuvoso e ameno e período seco no inverno, com noites frias. A precipitação pluvial média anual no município apresenta um total de $1724,2 \mathrm{~mm}$, com temperatura máxima já registrada de $36^{\circ} \mathrm{C}$, no verão, e mínima de $5^{\circ} \mathrm{C}$, no inverno. A temperatura média anual é de $18^{\circ} \mathrm{C}$, média das máximas de $26,4^{\circ} \mathrm{C}$ e média das mínimas de $14,3^{\circ} \mathrm{C}$. Nesse local o ensaio foi instalado em solo classificado como Latossolo Vermelho Distrófico típico A moderado, textura média, cuja análise química resultou: $\mathrm{pH}$ (água) $=6,3 ; \mathrm{P}=6,5 \mathrm{mgdm}^{-3} ; \mathrm{K}=39,0 \mathrm{mgdm}^{-3} ; \mathrm{Ca}=2,4 \mathrm{cmol}_{\mathrm{c}} \mathrm{dm}^{-3} ; \mathrm{Mg}=1,1 \mathrm{cmol}_{c} \mathrm{dm}^{-3} ;$ $\mathrm{Al}=0,0 \mathrm{cmol}_{c} \mathrm{dm}^{-3} ; \mathrm{H}+\mathrm{Al}=2,1 \mathrm{cmol}_{c} \mathrm{dm}^{-3} ; \mathrm{SB}=3,6 \mathrm{cmol}_{c} \mathrm{dm}^{-3} ; \mathrm{T}=5,7 \mathrm{cmol}_{c} \mathrm{dm}^{-3} ; \mathrm{V}=63,2 \%$; M.O. $=2,4$ dagkg $^{-1}$. Em ambos os locais foi realizada a calagem visando atingir $80 \%$ de saturação por bases, de acordo com a recomendação de Ribeiro et al. (1999).

As cultivares plantadas foram Albion, Aleluia e Aromas, caracterizadas por serem plantas de dias neutros, e Camarosa, Camino Real, Festival, Oso Grande e Ventana, por serem plantas de dias curtos. No processo de produção das mudas, utilizaram-se plantas matrizes oriundas de cultura de tecidos vegetais e plantadas em solo devidamente preparado, no qual foi feita a calagem de acordo com a análise do solo. As plantas matrizes foram plantadas em outubro de 2008 , em covas previamente adubadas com $3 \mathrm{~kg}$ de esterco bovino curtido e 100 gramas de superfosfato simples, no espaçamento de $2 \mathrm{~m} \times 1 \mathrm{~m}$. As plantas permaneceram no viveiro até início de maio de 2009, quando foram retiradas e preparadas para serem utilizadas nos experimentos. 0 preparo das mudas constou de limpeza (toalete), com aparação das folhas e excesso de raízes, além da seleção e padronização das mudas de acordo com o diâmetro da coroa, segundo os procedimentos recomendados por Antunes e Duarte Filho (2005).

O transplantio das mudas foi realizado no mês de maio de 2009, adotando-se a mesma metodologia para ambos os ensaios. 0 espaçamento foi de $0,4 m$ entre linhas e $0,3 m$ entre plantas. Os tratamentos foram dispostos em delineamento de blocos ao acaso, com parcelas subdivididas e quatro repetições com 30 plantas por sub-parcela. Os locais foram avaliados como tratamentos primários e as cultivares como tratamentos secundários. Até o completo pegamento das mudas, a irrigação foi realizada por aspersão convencional. Após o pegamento das mudas, instalou-se o sistema de irrigação localizada por gotejamento, o qual possibilitou o emprego da fertirrigação na adubação de cobertura. A seguir, foi feita a cobertura dos canteiros com filme de polietileno preto. Foram executados todos os tratos culturais, bem como as adubações convencionais de cobertura, de acordo com a análise foliar das plantas e as recomendações para a cultura do morangueiro (SANTOS; MEDEIROS, 2005). 
Semanalmente, de agosto a outubro de 2009 , os frutos foram colhidos no período da manhã e as seguintes variáveis analisadas: massa média de dez frutos (g), diâmetro transversal e longitudinal (mm), produção total por cultivar (gplanta-1), teor de sólidos solúveis totais ( ${ }^{\circ}$ Brix) e acidez titulável (\% ácido cítrico). Após a última colheita, foi feito o somatório de todas as colheitas para obtenção da produção total de frutos comerciais (g planta-1 ${ }^{-1}$ ). Os resultados foram submetidos à análise de variância, utilizando-se o software R versão 3.0.1 (R CORE TEAM, 2013), por meio dos pacotes ExpDes (FERREIRA et al., 2013) e stats (R CORE TEAM, 2013), e as médias foram comparadas pelo teste de Tukey a $5 \%$ de probabilidade.

\section{Resultados e discussão}

Na Tabela 1 são apresentados os resultados de produção total de frutos comerciais por planta e de massa média de frutos produzidos nos municípios de Maria da Fé e Inconfidentes. Foi observada interação significativa entre locais de cultivo e cultivares, porém, como cada cultivar se comportou de forma diferenciada em cada ambiente, consideraram-se as análises individuais.

Tabela 1 Produção total de frutos comerciais e massa média de frutos de oito cultivares de morangueiro em Maria da Fé e Inconfidentes- MG. Pouso Alegre, EPAMIG, 2009.

\begin{tabular}{|c|c|c|c|c|}
\hline \multirow{2}{*}{ Cultivares } & \multicolumn{2}{|c|}{ Produção total de frutos (gplanta ${ }^{-1}$ ) } & \multicolumn{2}{|c|}{ Massa média de fruto $(\mathrm{g})$} \\
\hline & Maria da Fé & Inconfidentes & Maria da Fé & Inconfidentes \\
\hline Albion & $220 \mathrm{c}$ & $319 \mathrm{bc}$ & $10,8 \mathrm{de}$ & $14,5 \mathrm{ab}$ \\
\hline Aleluia & $219 c$ & $268 c$ & $9,1 \mathrm{e}$ & $8,6 \mathrm{c}$ \\
\hline Aromas & $373 b$ & $275 c$ & $14,6 \mathrm{~cd}$ & $14,1 a b$ \\
\hline Camarosa & $393 b$ & $351 \mathrm{~b}$ & $17,1 \mathrm{bc}$ & $14,2 \mathrm{ab}$ \\
\hline Camino Real & $225 c$ & $278 \mathrm{bc}$ & 15,1 c & $13,6 \mathrm{~b}$ \\
\hline Festival & $219 c$ & $175 \mathrm{~d}$ & $15,2 \mathrm{c}$ & 18,2 a \\
\hline Oso Grande & $358 b$ & 512 a & $19,6 \mathrm{~b}$ & $15,1 \mathrm{ab}$ \\
\hline Ventana & 472 a & $334 \mathrm{bc}$ & 27,6 a & $15,2 \mathrm{ab}$ \\
\hline CV (\%) & 24,98 & 23,47 & 24,29 & 20,77 \\
\hline
\end{tabular}

Médias seguidas pela mesma letra na coluna não diferem entre si pelo teste de Tukey a $5 \%$ de probabilidade. Fonte: Elaboração dos autores.

Em Maria da Fé, as cultivares Ventana, Camorosa, Aromas e Oso Grande apresentaram produções de frutos comerciais por planta significativamente maiores em comparação com as demais cultivares, com destaque para a Ventana, que apresentou produção de 472 g planta-1 ${ }^{-1}$ além de representar produção de $20 \%$ superior à segunda cultivar mais produtiva, a Camarosa, com $393 \mathrm{~g}$ planta $^{-1}$. Nas condições de Inconfidentes, a cultivar Oso Grande se destacou com produção significativamente maior em relação às demais cultivares, com produção de $512 \mathrm{~g}$ planta ${ }^{-1}$, produção superior a $46 \%$ em relação à segunda cultivar mais produtiva, a Camorosa, com $351 \mathrm{~g}$ planta $^{-1}$. As cultivares que apresentaram as menores produções foram Aleluia (219 e 268 g planta-1 $^{-1}$, para as regiões de

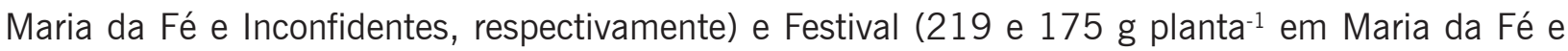
Inconfidentes, respectivamente).

As cultivares Ventana, Oso Grande e Camarosa foram mais produtivas, enquanto Festival e Aleluia, as menos produtivas, em ambos os locais. Duarte Filho (2006) avaliou nove cultivares de morangueiro em condições de campo, sem estrutura de proteção no cultivo, no município de Caldas, no Sul de Minas. Nessas cultivares, também observou maior rendimento produtivo da cultivar Cama- 
rosa, com produções de 665,51 (safra 2002) e 470,06 (safra 2003) gramas de frutos comerciais por planta, no primeiro e segundo ano consecutivo, contra 263,38 da cultivar Fern (safra 2002) e 146,11 da cultivar Tochiotome (safra 2003). 0 autor observou ainda que houve superioridade das cultivares Camarosa e Sweet Charlie nos três ambientes avaliados, e a Camarosa despontou em maior número de parâmetros que interessam ao mercado do fruto in natura. Confirma-se, portanto, o ótimo desempenho e adaptação dessa cultivar, visto que apresenta boa capacidade de frutificar mesmo sob condições de estresse, independente do ambiente de cultivo.

Pereira et al. (2013) observaram que as cultivares Aromas, Camarosa, Festival e Oso Grande apresentaram desempenho produtivo semelhantes, quando plantadas no mês de maio, em Bom Repouso, no sul de Minas, sob condições de campo e túnel baixo. Entretanto, nos plantios de junho e julho, a cultivar Oso Grande superou as demais cultivares. Já no plantio tardio, realizado em agosto, quando as temperaturas tendem a aumentar durante o período de produção, as cultivares Oso Grande e Aromas apresentaram melhor desempenho produtivo que as cultivares Camarosa e Festival. Esses resultados corroboram os obtidos em Maria da Fé e Inconfidentes, indicando a variação no desempenho produtivo entre as cultivares, de acordo com as variações ambientais. Apontam também para a viabilidade produtiva nestes municípios, de forma a oferecer opções de escolha da cultivar e da época de plantio e a apontar alternativas mais rentáveis de mercado.

Embora não apresentem tradição no cultivo do morangueiro, os municípios de Maria da Fé e Inconfidentes dispõem de condições climáticas favoráveis ao cultivo, além da proximidade de grandes centros consumidores como São Paulo, Rio de Janeiro e Belo Horizonte. A distância entre a localidade de cultivo e o mercado consumidor tem influência direta no ponto de colheita dos frutos. Com a proximidade entre o mercado consumidor e o produtor, pode-se colher os frutos com $75 \%$ da coloração vermelha para consumo in natura, o que constitui garantia de melhor qualidade e sabor.

Em Maria da Fé, com maior altitude e baixas temperaturas, o plantio pode ser antecipado para os primeiros meses do ano, obtendo-se, como resultado, uma produção antecipada e preços mais competitivos na comercialização. Além disso, a safra pode ser prolongada até os meses de novembro e dezembro, quando alcança preços mais elevados. Em Inconfidentes, com menor altitude e temperaturas mais elevadas, se comparadas às de Maria da Fé, o plantio pode ser realizado no mês de março. De acordo com Palha et al. (2013) o uso de cultivares indiferentes (de dias neutros) é uma alternativa viável, uma vez que possuem a particularidade de diferenciarem flores em qualquer época do ano, estando dependentes apenas da temperatura e não do fotoperíodo. Entretanto, os autores afirmam que existe uma interação temperatura/fotoperíodo específica para cada genótipo durante a iniciação floral, para que se obtenha boa frutificação. Portanto, tanto as temperaturas elevadas (acima de $28^{\circ} \mathrm{C}$ ) como as baixas temperaturas podem provocar uma redução na diferenciação floral, ocasionando diminuição da produção ao longo do ciclo. Como a implantação dos experimentos em Maria da Fé e Inconfidentes ocorreu no mês de maio, quando a temperatura já estava em declínio, o crescimento das plantas foi mais lento e, consequentemente, houve atraso no início da produção dos frutos. Portanto, com a redução do ciclo vegetativo, o número de colheitas e o rendimento de frutos foram consideravelmente reduzidos, o que explica os menores valores de produção obtidos para a maioria das cultivares.

No estudo de variedades em uma determinada região, é de suma importância a caracterização físico-química dos frutos para comprovar a qualidade do fruto (MOSCA et al., 2001). A cultivar Ventana foi a que se destacou na produção de frutos com maior massa média nas condições de cultivo de Maria da Fé (27,6 g), superando as demais cultivares (Tabela 1), o que está de acordo com Oliveira e Scivittaro (2011), que citam a massa média de frutos mais elevada (> 24,1 g) como caracterís- 
tica dessa cultivar. Em Inconfidentes, a cultivar Festival produziu frutos com maior massa (18,2 g), porém não diferiu estatisticamente das cultivares Albion, Aromas, Camarosa, Oso Grande e Ventana. A maior massa dos frutos da cultivar Festival pode ser atribuída ao reduzido número de frutos por planta, resultando em menor competição de frutos por planta e baixa produção total de frutos. A cultivar Aleluia apresentou frutos com menor massa média, em ambos os locais, bem abaixo de 12 g, o que, segundo Otto et al. (2009), seria o valor de massa média considerado de boa qualidade comercial. A cultivar Aleluia apresentou ainda baixa produtividade de frutos por planta em ambos os locais, mostrando pouca adaptação a essas condições de cultivo. Nas condições de Maria da Fé, a cultivar Albion também apresentou frutos com massa média inferior a 12 gramas.

A diferença entre os frutos quanto ao tamanho (Tabela 2) também foi significativa, e cada cultivar se comportou de forma diferenciada em cada ambiente, razão pela qual foram consideradas as análises individuais.

Tabela 2 Tamanho de frutos obtidos de oito cultivares de morangueiro em Maria da Fé e Inconfidentes- MG. Pouso Alegre, EPAMIG, 2009.

\begin{tabular}{lccccc}
\hline \multirow{2}{*}{ Cultivares } & \multicolumn{2}{c}{ Diâmetro longitudinal $(\mathrm{mm})$} & \multicolumn{3}{c}{ Diâmetro transversal $(\mathrm{mm})$} \\
\cline { 2 - 6 } & \multicolumn{1}{c}{ Maria da Fé } & Inconfidentes & \multicolumn{2}{c}{ Maria da Fé } & Inconfidentes \\
\hline Albion & $33,0 \mathrm{~cd}$ & $29,4 \mathrm{~d}$ & $25,6 \mathrm{e}$ & $22,4 \mathrm{c}$ \\
Aleluia & $28,5 \mathrm{~d}$ & $38,2 \mathrm{bc}$ & $21,4 \mathrm{f}$ & $29,9 \mathrm{ab}$ \\
Aromas & $36,7 \mathrm{bc}$ & $35,8 \mathrm{c}$ & $29,5 \mathrm{c}$ & $28,7 \mathrm{ab}$ \\
Camarosa & $35,0 \mathrm{bcd}$ & $38,2 \mathrm{bc}$ & $27,4 \mathrm{~d}$ & $26,8 \mathrm{~b}$ \\
Camino Real & $40,6 \mathrm{ab}$ & $42,3 \mathrm{ab}$ & $30,9 \mathrm{bc}$ & $31,8 \mathrm{a}$ \\
Festival & $40,7 \mathrm{ab}$ & $41,6 \mathrm{ab}$ & $30,5 \mathrm{bc}$ & $31,8 \mathrm{a}$ \\
Oso Grande & $39,7 \mathrm{abc}$ & $41,6 \mathrm{ab}$ & $31,3 \mathrm{ab}$ & $31,0 \mathrm{ab}$ \\
Ventana & $45,5 \mathrm{a}$ & $44,5 \mathrm{a}$ & $32,7 \mathrm{a}$ & $32,6 \mathrm{a}$ \\
\hline CV (\%) & 8,08 & 7,67 & 7,72 & 8,71 \\
\hline
\end{tabular}

Médias seguidas pela mesma letra na coluna não diferem entre si pelo teste de Tukey a $5 \%$ de probabilidade. Fonte: Elaboração dos autores.

A cultivar Ventana se destacou tanto no diâmetro longitudinal quanto no diâmetro transversal do fruto em ambos os ambientes (Tabela 2), o que está de acordo com Oliveira e Scivittaro (2011), que citam o maior tamanho dos frutos como característica dessa cultivar. Porém, a cultivar Ventana não diferiu estatisticamente das cultivares Oso Grande, Camino Real e Festival, em ambos os ambientes, quanto ao diâmetro longitudinal. A cultivar Aleluia apresentou frutos com menor diâmetro longitudinal, em ambos os locais, o que comprova a baixa adaptação dessa cultivar nessas condições ambientais. No diâmetro transversal do fruto, a cultivar Ventana, quando cultivada em Maria da Fé, destacou-se da maioria das cultivares, não diferindo apenas da Oso Grande. Já nas condições de Inconfidentes, não houve muitas variações entre as cultivares nessa variável, à exceção da cultivar Albion, que apresentou frutos com menor diâmetro transversal, e da cultivar Camarosa, que produziu frutos menores que Ventana, Festival e Camino Real.

Os resultados obtidos na avaliação das características químicas dos frutos são apresentados nas tabelas 3 e 4 . Foi observada interação entre cultivares e locais de cultivo para o teor de sólidos solúveis totais nos frutos (Tabela 3), porém, como cada cultivar se comportou de maneira diferenciada em cada ambiente, tornou-se necessário o estudo das análises individuais.

Tabela 3 Teores de Sólidos Solúveis Totais-SST ('Brix) e Acidez Titulável Total (\% de ácido cítrico) dos frutos de 
oito cultivares de morangueiro em Maria da Fé e Inconfidentes - MG. Pouso Alegre, EPAMIG, 2009.

\begin{tabular}{|c|c|c|c|}
\hline \multirow{2}{*}{ Cultivares } & \multicolumn{2}{|l|}{ SST (Brix) } & Acidez total (\% de ácido cítrico) \\
\hline & Maria da Fé & Inconfidentes & Maria da Fé e Inconfidentes \\
\hline Albion & $7,03 \mathrm{bc}$ & 8,71 a & $0,57 \mathrm{~d}$ \\
\hline Aleluia & $5,76 \mathrm{~cd}$ & 8,80 a & $0,62 \mathrm{~cd}$ \\
\hline Aromas & $5,66 \mathrm{~d}$ & $7,47 \mathrm{~b}$ & 0,82 a \\
\hline Camarosa & $7,13 \mathrm{~b}$ & $7,36 \mathrm{~b}$ & 0,88 a \\
\hline Camino Real & 8,63 a & 8,78 a & $0,72 b$ \\
\hline Festival & 8,56 a & $7,62 a b$ & $0,56 \mathrm{~d}$ \\
\hline Oso Grande & $7,52 a b$ & 5,79 c & $0,42 \mathrm{e}$ \\
\hline Ventana & 8,76 a & $5,92 \mathrm{c}$ & $0,69 \mathrm{bc}$ \\
\hline CV (\%) & 8,17 & 9,58 & 9,10 \\
\hline
\end{tabular}

Médias seguidas pela mesma letra na coluna não diferem entre si pelo teste de Tukey a $5 \%$ de probabilidade. Fonte: Elaboração dos autores.

Em Maria da Fé, as cultivares Camino Real, Festival e Ventana apresentaram maior teor de sólidos solúveis totais, destacando-se das cultivares Albion, Aromas, Aleluia e Camarosa; estatisticamente, porém, não diferiram da cultivar Oso Grande. As cultivares Aleluia, Albion, Camino Real e Festival produziram frutos com maior teor de sólidos solúveis totais, quando cultivadas em Inconfidentes, superando as demais cultivares, à exceção de Festival que se igualou estatisticamente às cultivares Aromas e Camarosa (Tabela 3).

De acordo com Chitarra e Chitarra (2005), é esperada uma variação nos teores de sólidos solúveis em frutos de morango (4 a $11^{\circ}$ Brix), e esta variação pode dar-se em função da espécie, da cultivar, do estádio de maturação e do clima. Os valores encontrados em ambos os experimentos, no presente trabalho, estão dentro desta faixa, visto que, em Inconfidentes, a cultivar Aleluia apresentou o maior teor $\left(8,80^{\circ}\right.$ Brix) e Oso Grande, o menor (5,79 ${ }^{\circ}$ Brix); e, em Maria da Fé, a cultivar Ventana apresentou o maior teor ( $8,76^{\circ}$ Brix) e a cultivar Aromas, o menor teor $\left(5,66^{\circ}\right.$ Brix). 0 teor de sólidos solúveis apresenta tendência de aumento com o avanço da maturação, pois são constituídos principalmente por açúcares (CHITARRA; CHITARRA, 2005).

Com relação à acidez titulável total dos frutos, a interação entre local e cultivar resultou em não significativa, indicando que esse parâmetro se comporta de forma semelhante em ambos os locais (Tabela 3). As cultivares Aromas e Camarosa apresentaram maior porcentagem de acidez titulável total e a cultivar Oso Grande, o menor percentual. Esse resultado contraria aqueles encontrados por Pádua et al (2006), que compararam as características físico-químicas de algumas cultivares de morangueiro, em que a cultivar Oso Grande obteve frutos com a maior acidez, quando comparada com a cultivar Camarosa. De acordo com Chitarra e Chitarra (2005), os frutos podem perder a acidez rapidamente com o processo de amadurecimento, mas, em alguns casos, pode haver um pequeno aumento nos valores de acidez com o avanço da maturação, o que possivelmente explica a diferença encontrada entre os teores de acidez do presente trabalho. Os frutos com maior teor de sólidos solúveis são mais interessantes para o mercado de frutos para o consumo in natura, que preferem frutos mais doces. Já os frutos com maior acidez são desejáveis para a industrialização (CAMARGO, 2008).

Conforme exposto na Tabela 4, não houve diferença significativa, entre as cultivares, com relação ao pH dos frutos, em cada ambiente testado, pois observou-se uma variação de 3,25 a 3,60, nos frutos produzidos em Maria da Fé, e um valor mais elevado, de 3,67 a 4,07, nos frutos produzidos em Inconfidentes. Esses valores estão bem próximos dos valores médios estipulados para o morango - considerado um fruto ácido-que é de aproximadamente 3,6 (CAMARGO, 2008).

Tabela 4 Teor de pH e Ratio (SST/AT) dos frutos de oito cultivares de morangueiro em Maria da Fé e Inconfidentes- 
MG. Pouso Alegre, EPAMIG, 2009.

\begin{tabular}{lrrrr}
\hline \multirow{2}{*}{ Cultivares } & \multicolumn{3}{c}{$\mathrm{pH}$} & Ratio (SST/AT) \\
\cline { 2 - 5 } & Maria da Fé & Inconfidentes & Maria da Fé & Inconfidentes \\
\hline Albion & $3,51 \mathrm{a}$ & $4,07 \mathrm{a}$ & $11,5 \mathrm{~b}$ & $16,3 \mathrm{a}$ \\
Aleluia & $3,52 \mathrm{a}$ & $4,04 \mathrm{a}$ & $8,7 \mathrm{c}$ & $15,5 \mathrm{ab}$ \\
Aromas & $3,25 \mathrm{a}$ & $3,97 \mathrm{a}$ & $6,7 \mathrm{c}$ & $9,4 \mathrm{~d}$ \\
Camarosa & $3,52 \mathrm{a}$ & $3,67 \mathrm{a}$ & $8,3 \mathrm{c}$ & $8,2 \mathrm{~d}$ \\
Camino Real & $3,57 \mathrm{a}$ & $4,04 \mathrm{a}$ & $12,4 \mathrm{~b}$ & $12,0 \mathrm{c}$ \\
Festival & $3,60 \mathrm{a}$ & $4,02 \mathrm{a}$ & $15,2 \mathrm{a}$ & $14,0 \mathrm{bc}$ \\
Oso Grande & $3,55 \mathrm{a}$ & $3,98 \mathrm{a}$ & $16,7 \mathrm{a}$ & $14,9 \mathrm{ab}$ \\
Ventana & $3,57 \mathrm{a}$ & $3,67 \mathrm{a}$ & $12,3 \mathrm{~b}$ & $8,9 \mathrm{~d}$ \\
\hline CV (\%) & 9,57 & 11,23 & 9,21 & 8,37 \\
\hline
\end{tabular}

Médias seguidas pela mesma letra na coluna não diferem entre si pelo teste de Tukey a $5 \%$ de probabilidade. Fonte: Elaboração dos autores.

Os resultados obtidos no presente trabalho corroboram aqueles obtidos por Pallamin (2007), que avaliou as cultivares Camarosa, Dover, Oso Grande e Sweet Charlie sob condições de campo, no município de Bauru-SP, com baixa altitude $(620 \mathrm{~m})$, obtendo valores médios de pH entre 3,22 e 3,35, e aqueles obtidos por Pádua et al. (2006), que também avaliaram o pH dos frutos de dez cultivares, oriundos do plantio em campo aberto no período de abril a setembro, nas condições serranas (altitude de $1370 \mathrm{~m}$ ) de Bom Repouso (Sul de Minas) e obtiveram resultados de 3,5 a 3,7.

Camargo (2008) cita que o pH do morango varia de acordo com seu estágio de desenvolvimento e que sua avaliação é importante para definir a finalidade de uso das cultivares, uma vez que o $\mathrm{pH}$ ácido é determinante para o morango destinado à indústria, enquanto os frutos menos ácidos são preferidos para o consumo in natura.

A determinação do teor de açúcares e dos ácidos orgânicos é importante para caracterizar o sabor, e a razão entre eles determina o "ratio" (açúcarácido-1), que é considerado um índice de qualidade para determinar o melhor tempo para a colheita do morango (CORDENUNSI et al., 2002). Quando o fruto está maduro, o sabor do morango é condicionado em parte pelo balanço entre os sólidos solúveis e a acidez titulável total (PADUA et al., 2006). Para esse parâmetro, foi observada interação significativa entre locais de cultivo e cultivares. Porém, como cada cultivar se comportou de forma diferenciada em cada ambiente, consideraram-se as análises individuais. Na Tabela 4, observa-se que, em Maria da Fé, as cultivares Oso Grande e Festival destacaram-se das demais com ratio de 16,7 e 15,2, respectivamente, enquanto Aleluia, Aromas e Camarosa apresentaram os menores valores para a essa relação. Em Inconfidentes, a cultivar Albion apresentou ratio de 16,2,superior ao das demais cultivares, porém não diferiu significativamente das cultivares Aleluia (ratio $=15,5$ ) e Oso Grande (ratio $=14,9$ ). Por outro lado, as cultivares Ventana, Camarosa e Aromas apresentaram os menores ratios. De forma geral, o ratio dos frutos da cultivar Oso Grande apresentou boa relação em ambos os ambientes (Tabela 4). Portanto, pode-se inferir que cada genótipo de morango apresenta características químicas influenciadas pelas localidades de cultivo.

\section{Conclusões}

As cultivares de morango que mais se adaptam às condições do Sul de Minas Gerais são Ventana, por produzir mais frutos em Maria da Fé, e a cultivar Oso Grande, por produzir mais frutos em Inconfidentes, conforme a seguinte sequência: Ventana $>$ Oso Grande $=$ Camarosa $=$ Aroma $>$ Abion 
$=$ Aleluia $=$ Camino Real $=$ Festival, para a região de Maria da Fé; e Oso grande $>$ Camarosa $=$ Camino Real $=$ Ventana $=$ Albion $=$ Aleluia $=$ Aroma $>$ Festival, para a região de Inconfidentes;

As cultivares Oso Grande e Camarosa apresentam maior estabilidade, com bom potencial produtivo em ambos os locais, configurando como opções para diversificação do plantio e da produção;

Os frutos das cultivares Camino Real, Festival, Oso Grande e Ventana são maiores e mais doces quando produzidos em Maria da Fé;

As condições de cultivo em Inconfidentes proporcionam frutos mais doces às cultivares Albion, Aleluia, Camino Real e Festival;

As cultivares Festival e Oso Grande, em Maria da Fé, e as cultivares Albion, Aleluia e Oso Grande, em Inconfidentes, produzem frutos com melhor sabor, conferido pelo equilíbrio entre açúcares e acidez.

\title{
Agradecimentos
}

À FAPEMIG pelo apoio financeiro e ao CNPq pela concessão de bolsa.

\section{Behavior of strawberry cultivars in Maria da Fé and Inconfidentes, southern state of Minas Gerais}

\begin{abstract}
Strawberry culture has expanded rapidly and numerous cultivars have been introduced in southern state of Minas Gerais. Most of these are introduced without prior assessments of the ecological conditions in the growing regions, which may lead some producers to failure, since the choice of cultivars is critical for the expected culture success. The characteristics of cultivars, the environmental conditions of the region and the management adopted will determine the yield and quality of the final product, influencing marketing due to the preference of markets for some fruit with specific characteristics. This study aimed to evaluate the productive aspects of cultivars Albion, Aleluia, Aromas, Camarosa, Camino Real, Festival, Oso Grande and Ventana in Maria da Fé, at the EPAMIG Experimental Farm and in Inconfidentes at the experimental area of the Federal Institute, southern state of Minas Gerais. Strawberry cultivars most suitable to conditions in southern Minas Gerais were Ventana for producing more fruits in Maria da Fé and Oso Grande for producing more fruits in Inconfidentes. Cultivars Oso Grande and Camarosa showed greater stability and good yield potential in both places, being options for planting and production diversification. Fruits of cultivars Camino Real, Festival, Oso Grande and Ventana were larger and sweeter when produced in Maria da Fé and the growing conditions of Inconfidentes provided sweeter fruit when cultivars Albion, Aleluia, Camino Real and Festival were used.
\end{abstract}

Keywords: Fragaria x ananassa Duch. Strawberry. Production. Fruit quality. 


\section{Referências bibliográficas}

ANTUNES, L. E. C.; DUARTE FILHO, J. Produção de mudas. In: ANTUNES, L.E.C.; DUARTE FILHO, J. Sistemas de produção do morango. Pelotas: EMBRAPA, 2005. Disponível em: <sistemasdeproducao.cnptia.embrapa.br/FontesHTML/Morango/SistemasProducaoMorango/index.htm>. Acesso em: 19 jul. 2014.

CAMARGO, L. K. P. Produtividade e qualidade de cultivares de morangueiro em sistemas orgânico e convencional na região de Guarapuava, PR. 2008. 86 p. Dissertação (Mestrado em Produção Vegetal). Universidade Estadual do Centro-Oeste, Unicentro-PR, Guarapuava.

CHITARRA, M. I. F.; CHITARRA, A. B. Pós-colheita de frutas e hortaliças: fisiologia e manuseio. 2 ed. Lavras: UFLA, 2005. 785p.

CORDENUNSI, B. R.; NASCIMENTO, J. R. O.; GENOVESE, M. I.; LAJOLO, F. M. Influence of cultivar on quality parameters and chemical composition of strawberry fruits grown in Brazil. Journal of Agriculture and FoodChemistry, Davis,v.50, p.2581-2586, 2002.

COSTA, H.; VENTURA, J. A. Doenças do morangueiro: diagnóstico de manejo. In: BALBINO, J.M.S. (Ed.). Tecnologias para produção, colheita e pós-colheita de morangueiro. Vitória: INCAPER, 2004. p. 39-56.

DUARTE FILHO, J. Cultivares de morango. In: CARVALHO, S. P. (Coord.). Boletim do morango: cultivo convencional, segurança alimentar, cultivo orgânico. Belo Horizonte: FAEMG, 2006. p. 9-14.

FERREIRA, E. B.; CAVALCANTI, P. P.; NOGUEIRA, D. A. ExpDes: Experimental Designs package. R packageversion 1.1.2. 2013. Disponível em: http://CRAN.R-project.org/package=ExpDes. Acesso em: 15 jul. 2013.

FILGUEIRA, F. A. R. Novo manual de olericultura: agrotecnologia moderna na produção e comercialização de hortaliças. Viçosa: UFV, 2000. 402p.

MOSCA, J. L.; SILVA, M. A. S.; EHLERT, P. A. D.; HIDALGO, A.; LIMA, J. R.; GOTO, R. Avaliação físico-química e sensorial de morango das cultivares 'Toyonoka' e 'Sweet Charlie'. Horticultura brasileira, Brasília, v.19, n.2, p.236-236, 2001.

OLIVEIRA, A. C. B.; BONOW, S. Novos desafios para o melhoramento genético da cultura do morangueiro no Brasil. Informe agropecuário, Belo Horizonte, v.33, n.268, p.21-26, 2012.

OLIVEIRA, F. M. Segurança alimentar e nutricional - Qualidade para o consumo.In: CARVALHO, S.P. (Coord.). Boletim do morango: cultivo convencional, segurança alimentar, cultivo orgânico. Belo Horizonte: FAEMG, 2006. p. 9-14.

OLIVEIRA, R. P.; SCIVITTARO, W.B. Desempenho produtivo de cultivares de morangueiro. Scientia Agraria, Curitiba, v.12, n.2, p.69-74, 2011.

OTTO, R. F.; MORAKAMI R. K.; REGHIN, M. Y; CAIRES, E.F. Cultivares de morango de dia neutro: produção em função de doses de nitrogênio durante o verão. Horticultura brasileira, Brasília, v.27, p.217-221, 2009. 
PÁDUA, J. G.; MOTA, R. V.; DUARTE FILHO, J.; CAPRONI, C. M.; GONÇALVES, F. M. Características físico-química de frutos de cultivares de morangueiro. In: SIMPÓSIO NACIONAL DO MORANGO E II ENCONTRO SOBRE PEQUENAS FRUTAS E FRUTAS NATIVAS DO MERCOSUL, 3, 2006, Pelotas: Embrapa Clima Temperado. Anais... Pelotas, 2006. 1 CD-ROM.

PALHA, M. G.; CAMPO, J. C.; SOUSA, M. B.; RAMOS, A. C.; SERRANO, M. C.; ALMEIDA, L. H. Comparação de dois sistemas de produção de morango, em substratos e em solo, tendo em vista a obtenção de frutos no outono. CONGRESO ÍBÉRICO DE AGROINGENIERIA Y CIENCIAS HORTÍCOLAS, 2013, Madrid, Anais eletrônicos... Madri, 2013. Disponível em: <http://sechaging-madrid2013.org/ geystiona/adjs/comunicaciones/272/P02710003.pdf>. Acesso em: 19 jul. 2014.

PALLAMIN, M. L. Alternativas no controle fitossanitário em diferentes cultivares de morangueiro como ferramenta na produção integrada. 2007. 75p. Dissertação (Mestrado em Agronomia). Universidade Estadual Paulista "Júlio Mesquita", Botucatu.

PEREIRA, W. R.; SOUZA, R. J.; YURI, J. E.; FERREIRA, S. Produtividade de cultivares de morangueiro, submetidas a diferentes épocas de plantio. Horticultura brasileira, Brasília, v.31, n.3, p.500-503, 2013.

R CORE TEAM. R: A language and environment for statisticalcomputing. R Foundation for StatisticalComputing, Vienna. 2013. Disponível em: <http://www.R-project.org>. Acesso em: 15 jul. 2013.

RIBEIRO, A.C.; GUIMARÃES, P.T.G.; ALVAREZ, V.H. Recomendações para o uso de corretivos e fertilizantes em Minas Gerais: $5^{a}$ aproximação. Viçosa: SBCS. 1999.359p.

SANTOS, A. M.; MEDEIROS, A. R. M. Nutrição, calagem e adubação. In: ANTUNES, L.E.C.; DUARTE FILHO, J. Sistemas de produção do morango. Pelotas: Embrapa, 2005. Disponível em:

http://sistemasdeproducao.cnptia.embrapa.br/FontesHTML/Morango/SistemaProducaoMorango/ cap05.htm Acesso em: 19 jul. 2014.

\section{Histórico}

Submetido em: 07/05/2013

Aceito em: 17/09/2014 